\title{
Beyond headline mitigation numbers: we need more transparent and comparable NDCs to achieve the Paris Agreement on climate change
}

\author{
W. P. Pauw ${ }^{1,2,3}$ (D) Richard J. T. Klein ${ }^{4,5}$. \\ Kennedy Mbeva ${ }^{6,7}$ - Adis Dzebo ${ }^{1,2,3}$. \\ Davide Cassanmagnago ${ }^{8}$ • Anna Rudloff ${ }^{9}$
}

Received: 24 July 2017 / Accepted: 1 December 2017 / Published online: 19 December 2017

(C) The Author(s) 2017. This article is an open access publication

\begin{abstract}
Nationally determined contributions (NDCs) were key to reaching the Paris Agreement and will be instrumental in implementing it. Research was quick to identify the 'headline numbers' of NDCs: if these climate action plans were fully implemented, global mean warming by 2100 would be reduced from approximately 3.6 to $2.7^{\circ} \mathrm{C}$ above pre-industrial levels (Höhne et al. Climate Pol 17:1-17, 2016; Rogelj et al. Nature 534:631-639, 2016). However, beyond these headline mitigation numbers, NDCs are more difficult to analyse and compare. UN climate negotiations have so far provided limited guidance on NDC formulation, which has resulted in varying scopes and contents of NDCs, often lacking details concerning ambitions. If NDCs are to become the long-term instrument for international cooperation, negotiation, and ratcheting up of ambitions to address climate change, then they need to become more transparent and comparable, both with respect to mitigation goals, and to issues such as adaptation, finance, and the way in which NDCs are aligned with national policies. Our analysis of INDCs and NDCs (Once a party ratifies the Paris Agreement, it is invited to turn its Intended Nationally Determined Contribution
\end{abstract}

\section{W. P. Pauw}

w.p.pauw@gmail.com

1 German Development Institute, Bonn, Germany

2 Stockholm Environment Institute, Stockholm, Sweden

3 Utrecht University, Utrecht, Netherlands

4 Stockholm Environment Institute, Bonn, Germany

5 Centre for Climate Science and Policy Research, Linköping University, Linköping, Sweden

6 African Centre for Technology Studies, Nairobi, Kenya

7 University of Melbourne, Melbourne, Australia

8 Independent Researcher, Milan, Italy

9 Kiel University, Kiel, Germany 
(INDC) into an NDC. We refer to results from our INDC analysis rather than our NDC analysis in this commentary unless otherwise stated.) shows that they omit important mitigation sectors, do not adequately provide details on costs and financing of implementation, and are poorly designed to meet assessment and review needs.

Intended NDCs (INDCs) were key to reaching the Paris Agreement. As many as 159 parties submitted their INDCs before the UN climate negotiations in Paris, including major greenhouse gas emitters such as the European Union, China, and the USA, but also many vulnerable countries, including Least Developed Countries and Small Island Developing States. The nearuniversal submission of INDCs, in which countries documented their proposed contributions to address climate change, helped to circumvent the contentious differentiation between Annex I (developed) and non-Annex I (developing) country groups (Mbeva and Pauw 2016).

The NDCs will also be key to implementing the Paris Agreement, because they outline countries' contributions to reduce or limit greenhouse gas emissions until at least 2025. As this Letter will show, this bottom-up approach allowed developing countries also to include other priorities, such as adaptation and finance, thus creating political buy-in.

Countries' proposed contributions to global greenhouse gas emission reductions gave rise to the immediate 'headline numbers' of the NDCs. Although these are important, the NDCs are meant to provide further substance. However, the Lima Call for Climate Action (UNFCCC 2014; Decision 1/CP.20), the main outcome of the 2014 climate negotiations in Lima, Peru, offered limited guidance on nationally determined contributions (NDC) scope and content (Mbeva and Pauw 2016). Subsequent negotiation sessions in Paris, France, and Marrakesh, Morocco, have not provided further detail, as it proved difficult to reach agreement among all countries (see IISD 2016). As a result, countries have been free to choose whether or not to 'consider' adaptation (Decision 1/CP.20, para 12); how to interpret 'clarity, transparency, and understanding' (para 13); how to formulate a mitigation contribution (para 14); and how to consider its contribution to be 'fair and ambitious' (para 14). Moreover, there is no guidance on the role of finance in implementing NDC, despite its importance.

As a result, NDCs vary in scope, content, and length. They range from 3 to 57 pages, and often lack detail about stated ambitions. This variation hinders a robust understanding of countries' ambitions and priorities, and how they compare among one another (Van Asselt et al. 2015; Carraro 2016; Kurdziel et al. 2016).

Earlier work to address issues beyond NDCs' headline numbers is limited in scope and detail. For example, Rogelj et al. (2016) mention that INDCs raise issues such as adaptation, equity, and financing, but hardly elaborate on this. The NDC Platform of the World Bank (2017) is geared towards Development Banks and investors and focuses on financial and cost aspects. The scope of another online tool to compare INDCs, WRI CAIT, is limited to 11 categories. Its single category on adaptation indicates merely whether or not adaptation is included (see WRI 2017). Neither the NDC Platform nor CAIT includes all INDCs, nor are they being updated with new NDCs. More detailed analysis of adaptation in NDCs is provided by UNEP (2015). UNEP finds that adaptation costs in NDCs exceed current adaptation finance provided by developed countries, and that NDCs illustrate that there are similarities between types of climate risks and adaptation responses, although it does not quantify those. USAID (2016) also discusses adaptation priority sectors, as well as issues including mitigation, finance, and technology needs. However, it is based on 37 INDCs only. Sector-specific analyses have also been conducted. For example, Petersen and Braña Varela (2015) focus on the role of the INDCs in the forest sector; Cran and Durand (2015) review the integration of 


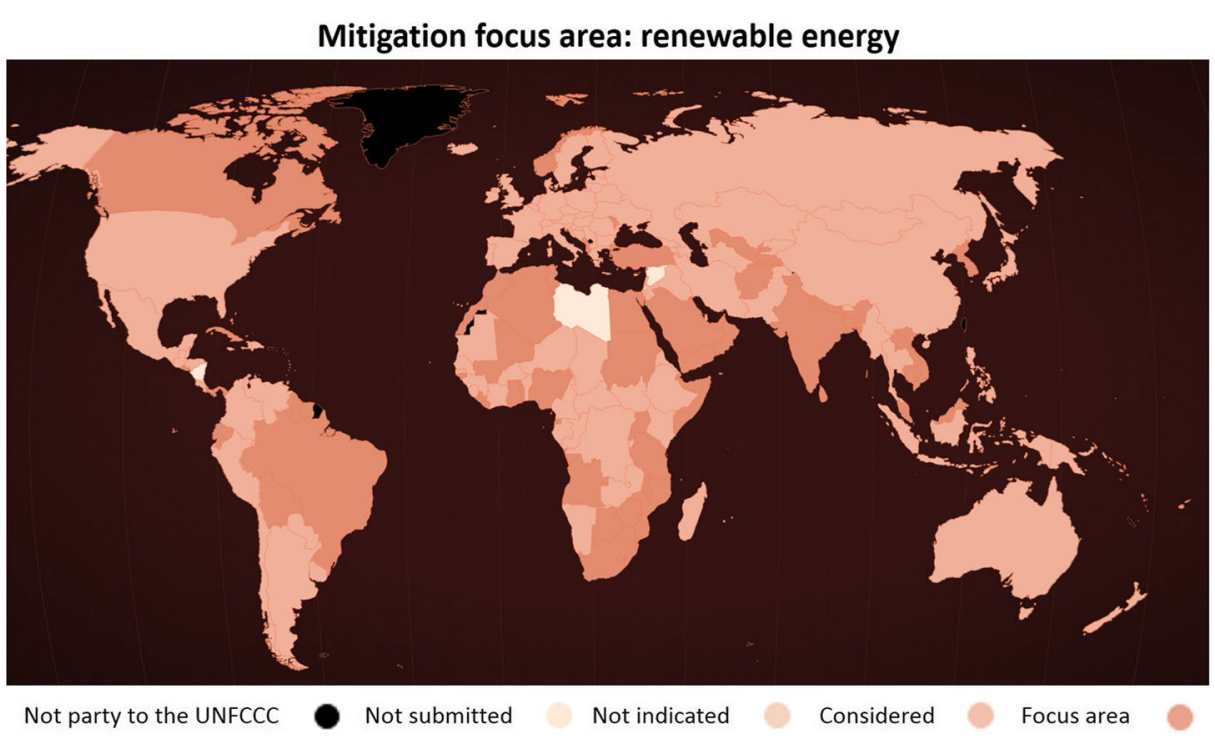

Fig. 1 Renewable energy as a mitigation focus area in INDCs (based on Pauw et al. 2016)

water issues in the INDCs; and Strohmaier et al. (2016) highlight the role of agriculture in the INDCs. Arguably, the secretariat of the United Nations Framework Convention on Climate Change (UNFCCC) provided the most comprehensive overview of INDCs in their synthesis report (UNFCCC 2015a) - but it is based on INDCs only. Despite the plethora of work on INDCs and NDCs, a comprehensive source of data and information has been lacking.

We have extended the database used by the UNFCCC for their synthesis report with 60 subcategories on mitigation, adaptation, finance and support, planning and process, and 'broader picture' issues such as links to green growth strategies, and Sustainable Development Goals (SDGs). This resulted in the first comprehensive database of all current INDCs $(N=165)$ and NDCs $(N=133)$, which is accessible and visualised ${ }^{1}$ through the NDC Explorer, an online interactive tool (see Pauw et al. 2016). This Letter is based on analyses conducted with this tool.

To create more transparency and to be able to compare NDCs, the NDC Explorer aims to capture the diversity in scope, content and level of detail of INDCs and NDCs through universal single categories with distinct legend items. It is challenging to generalise and capture diverse data in such categories while at the same time providing detail for individual countries. The tool does not interpret or judge countries' ambitions but rather generates transparency and comparability useful for many actors, including policymakers, civil society, and researchers. Examples of each of the tool's five main categories illustrate this point.

On mitigation, the NDC Explorer shows that promoting renewable energy is the most common mitigation strategy, with 87 INDCs making it a priority (see Fig. 1). Many countries specify the kinds of renewable energy sources they aim to expand, including solar (59 times) and wind (38 times). This is a clear signal to the renewable energy sector. On the other hand, few INDCs include agriculture or transport as focus areas for mitigation, even though these two sectors, along with energy and industry, are the largest contributors to greenhouse gas emissions (Blanco et al. 2014).

\footnotetext{
${ }^{1}$ The NDC Explorer data will be made available online at www.NDCexplorer.info in early 2018. For technical reasons, it has not been possible to do so earlier. Please contact Pieter.Pauw@die-gdi.de if you are interested in accessing the data before they are available online.
} 
Although options to reduce the transport sector's energy intensity and emissions have been known for over two decades (e.g. Chapman 2007; Michaelis and Davidson 1996), only 15 INDCs list the sector as a priority. Most INDCs mention mitigation in agriculture, but only five prioritise it. This number is surprisingly low given that many developing countries consider it controversial in the UN climate negotiations (Kaplan 2012). Another potential omission is carbon capture and storage (CCS). Many analysts see CCS as a key strategy for achieving steep declines in greenhouse gas emissions (see also Boucher et al. 2016). However, only 11 INDCs mention CCS. Unless more countries prioritise CCS, the political and technical feasibility of CCS is likely to remain uncertain at the scale and in the timeframe necessary (see Jordan et al. 2013).

On adaptation, our analysis shows significant differences when comparing developed and developing countries. The former hardly mention adaptation, while many of the latter prioritise it. For example, 38 developing country INDCs include quantitative adaptation targets (see Fig. 2), mostly in forestry (17 INDCs) and water (16 INDCs). Such quantitative targets could inform the development of adaptation metrics under the UNFCCC. Although the NDC formulation guidelines only 'invite' countries to include adaptation in their NDCs, it is unfortunate that only developing countries have included quantitative targets. Developed countries tend to omit adaptation from their INDCs even though many of them have domestic adaptation plans and policies in place (Ford et al. 2015). This omission also ignores transnational (spillover) effects of climate change, as transmitted through global supply chains, financial systems, migration, and shared natural resources (Benzie et al. 2016). A decision by the UNFCCC on the relationship between NDCs and adaptation reporting obligations and instruments (including Adaptation Communications and National Adaptation Plans) would increase transparency, especially if more countries included adaptation in their NDCs.

Our analysis of INDCs' coverage of finance and support reveals that 99 INDCs make mitigation contributions partly or wholly conditional on receiving international financial support. Seventy-seven percent of the low-income countries describe the need for support, and $75 \%$ of the low- to middle-income countries do so (see Fig. 3). A high number of INDCs (71

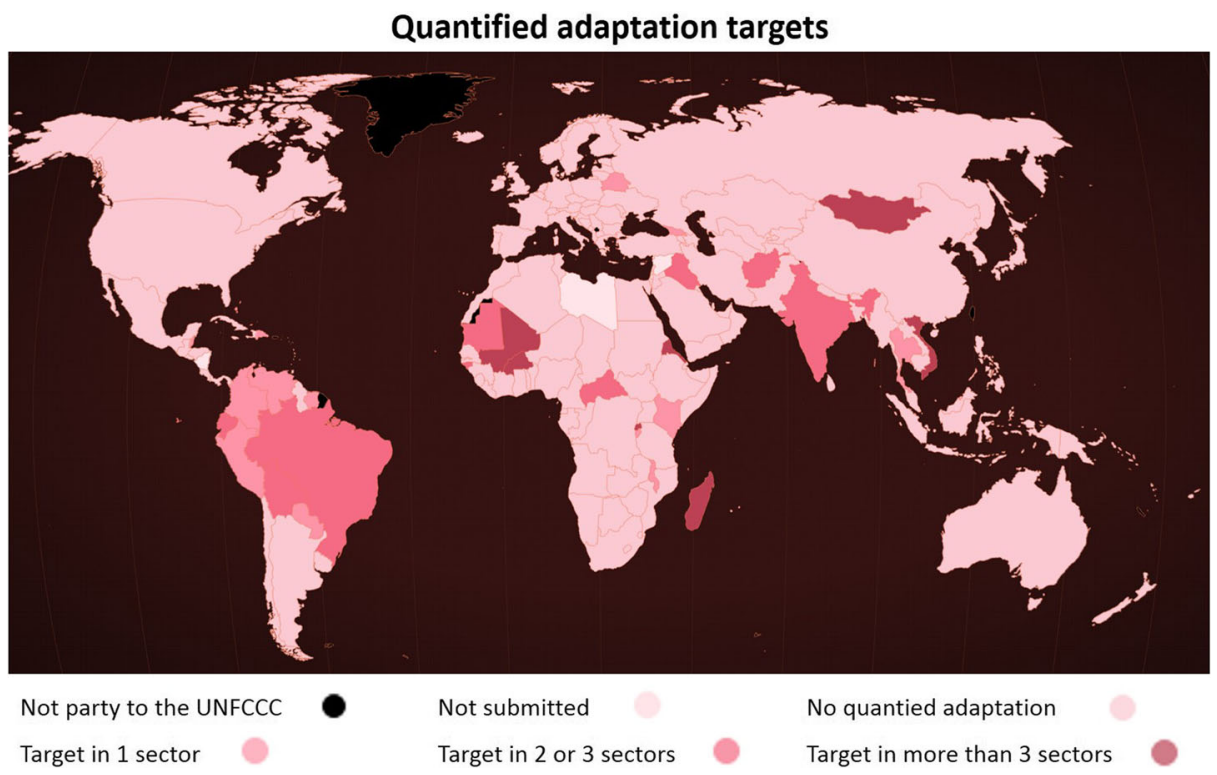

Fig. 2 Inclusion of quantified sectoral adaptation targets in INDCs (based on Pauw et al. 2016) 


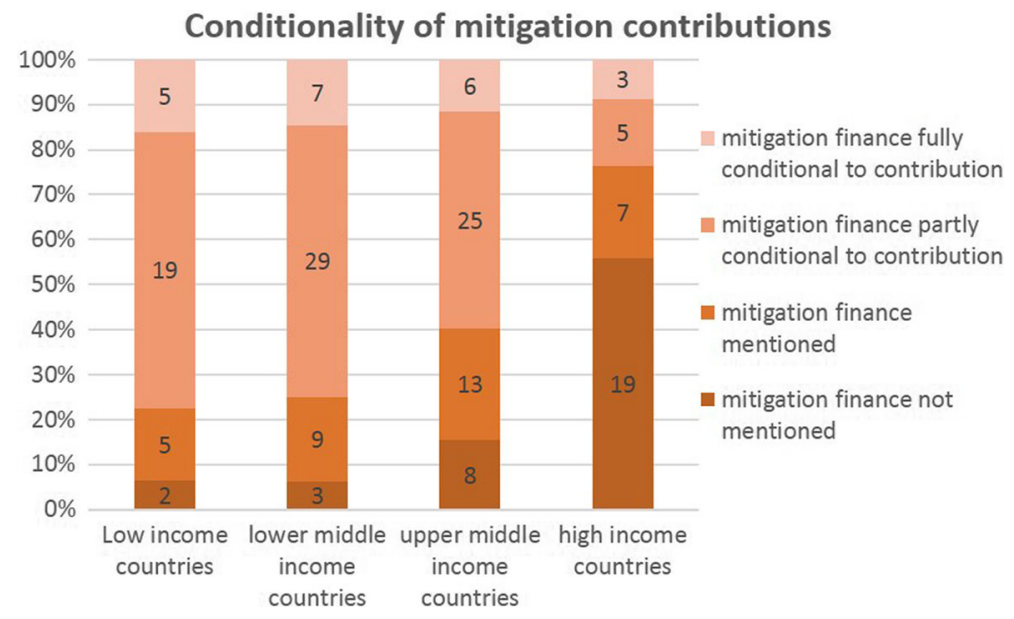

Fig. 3 Conditionality of mitigation contributions in INDCs by country income groups (based on Pauw et al. 2016)

including $61 \%$ of the low-income countries) do the same for adaptation. Yet, developed countriesthe expected sources of financial support — hardly discuss finance or other support in their INDCs. The financial commitments made to date suggest that it is unlikely that developed countries will provide sufficient finance to meet the expectations stated in developing countries' INDCs. Unmet financial conditions impair the viability of developing countries' NDCs, and therefore undermine NDCs as a successful instrument for post-Paris international climate policy.

All 165 INDCs except two include information on the planning, formulation, and implementation process. Seventy-eight percent of the INDCs highlight the importance of preparatory elements such as consultations, public awareness campaigns, and inter-governmental coordination. Nearly two-thirds of the INDCs mentioned the involvement of particular stakeholders in the formulation process (principally civil society and private sector representatives), which is seen as crucial for transparency (Dodwell et al. 2016). In contrast to the high transparency on INDC formulation and implementation, however, assessment and review are hardly mentioned. International assessment and review of NDCs can help to ensure that NDCs comply with internationally agreed objectives and principles, by establishing and enhancing transparency, trust and accountability between Parties. In addition, assessment and review can help to increase ambition by providing an opportunity for feedback and exchange of ideas and approaches, and by encouraging additional reciprocal actions (Van Asselt et al. 2015). However, these opportunities for clarification, increasing transparency, and for learning from comparing are missed as only 11 INDCs refer to international assessment and review processes.

Finally, we examined how the INDCs connect to broader national and international policy processes. For example, in line with developing countries' longstanding tradition of linking environmental politics to sustainable development (Najam 2005), most developing countries indicate that they will implement their INDC in the context of sustainable development. However, only ten INDCs explicitly mention the SDGs. A possible explanation is that Agenda 2030 was still under development when countries formulated their INDCs. Indeed, of the nine countries that altered their INDCs before submitting them as NDCs, Morocco, Indonesia, Pakistan, and Sri Lanka all explicitly added SDGs. Another interesting example is that the INDCs of major oil-producing countries, including Nigeria, Saudi Arabia, and Venezuela, mention plans for fossil fuel subsidy reforms. Clarity on the links between policy fields can foster policy coherence and harness co- 
benefits. The comparison of INDCs can also help countries to learn from each other about how to link policy fields.

The NDC Explorer helps to provide more transparency and to increase comparability by enabling detailed aggregate and comparative analysis of both INDCs and NDCs. This serves at least three purposes. First, it reveals some of the weaknesses of the scope and content of NDCs, including the omission of important mitigation sectors and the limited focus on assessment and review. Second, it can support civil society to hold governments accountable for implementing NDCs. Third, increased transparency in particular can help actors such as development banks and climate funds to check whether their climate projects address the NDCs and to mainstream climate change in the broader project portfolio.

For the research community, the NDC Explorer provides only a stepping stone. Before countries start formulating their second NDC in 2020, research is needed to analyse further weaknesses (apart from limited transparency and comparability) associated with the current NDC process and to identify ways of addressing those; to provide suggestions for methods and metrics for NDCs; and to analyse how to engage investors and development organisations and NGOs in NDC implementation. In turn, such research serves to support the UN climate negotiations by informing the development of common issues, methods, and metrics for NDCs. This is essential for tracking countries' progress made in implementing and achieving NDCs, to review NDCs, and for countries to submit new and more ambitious NDCs every 5 years (see UNFCCC 2015b; Victor et al. 2017). Despite the critique presented in this Letter, we are convinced that such research can make NDCs a crucial instrument for international cooperation and ratcheting up of ambitions to address climate change effectively.

Open Access This article is distributed under the terms of the Creative Commons Attribution 4.0 International License (http://creativecommons.org/licenses/by/4.0/), which permits unrestricted use, distribution, and reproduction in any medium, provided you give appropriate credit to the original author(s) and the source, provide a link to the Creative Commons license, and indicate if changes were made.

\section{References}

Benzie M, Hedlund J, Carlsen H (2016) Introducing the transnational climate impacts index: indicators of country-level exposure - methodology report. Stockholm Environment Institute Working Paper No. 201607. Stockholm. https://www.sei-international.org/publications?pid=2972

Blanco G, Gerlagh R, Suh S, Barrett J, de Coninck HC, Diaz Morejon CF, Mathur R, Nakicenovic N, OfosuAhenkora A, Pan J, Pathak H, Rice J, Richels R, Smith SJ, Stern DI, Toth FL, and Zhou P (2014) Drivers, trends and mitigation. In: Climate change 2014: mitigation of climate change. Contribution of Working Group III to the Fifth Assessment Report of the Intergovernmental Panel on Climate Change. Cambridge University Press: Cambridge

Boucher O, Bellassen V, Benveniste H, Ciais P, Criqui P, Guivarch C, Le Treut H, Mathy S, Séférian R (2016) Opinion: in the wake of Paris agreement, scientists must embrace new directions for climate change research. PNAS 113(27):7287-7290

Carraro C (2016) A bottom-up, non-cooperative approach to climate change control: assessment and comparison of nationally determined contributions (NDCs). J Sustain Dev 9(5):175

Chapman L (2007) Transport and climate change: a review. J Transp Geogr 15(2007):354-367

Cran M, Durand (2015) Review of the integration of water within the intended nationally determined contributions (INDCs) for COP21. http://www.iwa-network.org/downloads/1448965142-2015\%2011\%2029_ Review\%20of\%20Water\%20integration\%20in\%20INDC_VF.pdf

Dodwell C, Harries J, Holdaway E, Horrocks L, Mittal N, Saddington D, Shabb K, Smithers R, Le-Cornu E, Wartmann S, Monkhouse C, Sura K (2016) Planning for NDC implementation. Quick start guide and reference manual. Climate and Development Knowledge Network, London. https://www.cdkn.org/ndcguide/wp-content/uploads/2016/12/Quick-Start-Guide-final-pdf.pdf 
Ford D, Berrang-Ford L, Biesbroek R, Araos M, Austin SE, Lesnikowski A (2015) Adaptation tracking for a post-2015 climate agreement. Nat Clim Chang 5:967-969

Höhne N, Kuramochi T, Warnecke C, Röser F, Fekete H, Hagemann M, Day T, Tewari R, Kurdziel M, Sterl S, Gonzales S (2016) The Paris Agreement: resolving the inconsistency between global goals and national contributions. Clim Pol 17:1-17

IISD (2016) Earth negotiations bulletin. Summary of the marrakech climate change conference: 7-19 Nov 2016. International Institute for Sustainable Development. http://enb.iisd.org/download/pdf/enb12689e.pdf

Jordan A, Rayner T, Schroeder H, Adger N, Anderson K, Bows A, Le Quéré C, Joshi M, Mander S, Vaughan N, Whitmarsh L (2013) Going beyond two degrees? The risks and opportunities of alternative options. Clim Pol 13(6):751-769

Kaplan M (2012) Agriculture in the international climate negotiations - supporting sustainable development or just dubious emission reductions? DIE Policy Brief 16/2012. https://www.die-gdi. de/uploads/media/BP 16.2012.pdf

Kurdziel M, Day T, Roeser F, von Lüpke H, Herrmann L, Zachow I (2016) Challenges and lessons learned in the preparation of Intended Nationally Determined Contributions (INDCs). Deutsche Gesellschaftfür Internationale Zusammenarbeit (GIZ), Eschborn

Mbeva KL, Pauw WP (2016) Self-differentiation of countries' responsibilities: addressing climate change through Intended Nationally Determined Contributions. German Development Institute/Deutsches Institut für Entwicklungspolitik (DIE), Discussion Paper 4/2016. ISBN: ISSN 1860-0441

Michaelis L, Davidson O (1996) GHG mitigation in the transport sector. Energy Policy 24(10/11):969-984

Najam A (2005) Developing countries and global environmental governance: from contestation to participation to engagement. Int Environ Agreements 5(3):303-321

Pauw WP, Cassanmagnano D, Mbeva K, Hein J, Guarin A, Brandi C, Dzebo A, Canales N, Adams KM, Atteridge A, Bock T, Helms J, Zalewski A, Frommé E, Lindener A, Muhammad D (2016) NDC explorer. German Development Institute/Deutsches Institut für Entwicklungspolitik (DIE), African Centre for Technology Studies (ACTS), Stockholm Environment Institute (SEI). www.NDCexplorer.info DOI: https://doi.org/10.23661/ndc_explorer_2017_2.0

Petersen K, Braña Varela J (2015). NDC analysis: an overview of the forest sector. World Wide Fund for Nature (WWF). http://d2ouvy59p0dg6k.cloudfront.net/downloads/r2_wwf_inde_brief.pdf

Rogelj J, Den Elzen M, Höhne N, Fransen T, Fekete H, Winkler H, Schāeffer R, Sha F, Riahi K, Meinshausen M (2016) Paris Agreement climate proposals need a boost to keep warming well below $2^{\circ} \mathrm{C}$. Nature 534(7609): $631-639$

Strohmaier R, Rioux J, Seggel A, Meybeck A, Bernoux M, Salvatore M, Miranda J, Agostini A (2016) The agriculture sectors in the Intended Nationally Determined Contributions: analysis. Food and Agriculture Organization of the United Nations, Rome

UNEP (2015) The adaptation finance gap update: with insights from the INDCs. United Nations Environment Programme (UNEP), Nairobi

UNFCCC (2014) Decision 1/CP.20. Lima call for action. UNFCCC, Bonn. http://unfecc.int/resource/docs/2014 /cop20/eng/10a01.pdf\#page=2

UNFCCC (2015a) Synthesis report on the aggregate effect of the intended nationally determined contributions. https://unfccc.int/resource/docs/2015/cop21/eng/07.pdf

UNFCCC (2015b) Adoption of the Paris agreement. Bonn: https://unfccc.int/resource/docs/2015/cop21/eng/109 r01.pdf

USAID (2016) Analysis of Intended Nationally Determined Contributions (INDCs). USAID, Washington D.C

Van Asselt H, Sælen H, Pauw P (2015) Assessment and review under a 2015 climate change agreement. Nordic Council of Ministers, Copenhagen. https://doi.org/10.6027/TN2015-530. http://norden.diva-portal. org/smash/get/diva2:797336/FULLTEXT01.pdf

Victor DG, Akimoto K, Kaya Y, Yamaguchi M, Cullenward D, Hepburn C (2017) Prove Paris was more than paper promises. Nature 548:25-27

World Bank (2017) NDC Platform. http://spappssecext.worldbank.org/sites/indc/Pages/INDCHome.aspx

WRI (2017) CAIT Paris contributions map. http://cait.wri.org/indc/\#/map 